Proceedings

\title{
Cusps Deformation of MOD Cavities Restored with High-Viscosity and Low-Viscosity Bulk-Fill Composites through the Bulk-Fill and the Incremental Layering Techniques ${ }^{\dagger}$
}

\author{
Vito Gallicchio ${ }^{1}{ }^{*}$, Roberto De Santis ${ }^{2}$, Vincenzo Lodato ${ }^{1}$, Gianrico Spagnuolo ${ }^{1}$ and \\ Carlo Rengo $^{3}$ \\ 1 Department of Neurosciences, Reproductive and Odontostomatological Sciences, University "Federico II" \\ of Naples, via S. Pansini 5, 80131 Naples, Italy; vincenzo.lodato@unina.it (V.L.); gspagnuo@unina.it (G.S.) \\ 2 Institute of Polymers, Composites and Biomaterials - National Research Council of Italy, V.le J.F. Kennedy \\ 54-Mostra d'Oltremare Pad. 20, 80125 Naples, Italy; rosantis@unina.it \\ 3 Department of Prosthodontics and Dental Materials, University of Siena, Siena 53100, Italy; \\ carlorengo@alice.it \\ * Correspondence: vito.gallicchio@unina.it; Tel.: +39-333-767-0760 \\ + Presented at 1st International Electronic Conference on Applied Sciences, 10-30 November 2020; \\ Available online: https://asec2020.sciforum.net/.
}

Published: 10 November 2020

\begin{abstract}
Background: Bulk-fill resin composites have a high depth of cure, and cavity with a depth even higher than $4 \mathrm{~mm}$ can be restored though a single step with the bulk-fill technique. A main concern of bulk-fill composites is the shrinkage stress developing at the composite-tooth walls interface, potentially higher than that developed through the incremental layering technique. The aim of this study is to investigate cusps deformation caused by material shrinkage during photopolymerization. Methods: Two bulk-fill composite materials, with high-viscosity and lowviscosity and a different material composition, were characterised through linear shrinkage and compressive tests. Using both the bulk-fill and the incremental layering techniques for the restoration of mesio-occlusal-distal cavities of human premolars, cusps distance variation was evaluated. Results: The low-viscosity composite presents a significantly higher shrinkage value $(p<0.05)$ than the high-viscosity composite, while mechanical properties such as strength and the Young's modulus of the high-viscosity composite are significantly higher $(p<0.05)$. No significant difference has been observed for cusps deformation in both the composite materials according to mesioocclusal-distal cavities restored through the bulk-fill or the incremental layering techniques. Conclusions: Although for the high-viscosity composite, a lower cusps deformation would be expected, no significant difference has been observed between the composite materials. This result can be ascribed to the higher Young's modulus value of the high-viscosity composite. This suggests that the high-viscosity composite is stiffer, while the low-viscosity composite is more compliant, thus balancing the cusps distance variation.
\end{abstract}

Keywords: cuspal deformation; bulk-fill composites; linear shrinkage; extensometer; mechanical properties

\section{Introduction}


Resin Based composites are largely used for conservative dentistry from decades, although these materials are affected by volumetric shrinkage during curing. This aspect is one of the main concerns for a good restoration. The volumetric shrinkage produced by material polymerization can cause a high stress at the tooth-composite interface, with a consequent dangerous adhesive debonding and/or cuspidal deformation [1,2]. Different techniques and materials have been developed to reduce this risk. The incremental layering technique is used in direct restorations to modify shrinkage directions by filling the tooth cavity with increments of traditional composite resins [3]. The main concern of this technique is the longer chair time required to make two or more increments and cures $[4,5]$.

A new filling method is possible thanks to the high translucency and a powerful initiator system of bulk-fill resin composites. This filling method is the bulk-fill technique and consists in filling the tooth cavity in a single step, with a single photopolymerization. Bulk-fill composite materials have a high depth of cure and cavities with a depth even higher than $4 \mathrm{~mm}$ can be restored through a single increment [6,7]. In the last years many bulk-fill composites, with different rheological properties and material composition, have been developed. Bulk-fill composites can be classified, by rheological properties, in high-viscosity (viscosity higher than $100 \mathrm{kPa} \cdot \mathrm{s}$ ) and low-viscosity materials (viscosity lower than $1 \mathrm{kPa} \cdot \mathrm{s}$ ) [8]. Low viscosity bulk-fill composites can be injected into the tooth cavity with a needle, while high-viscosity composites are applied and shaped through a spatula or in some cases through a vibration handpiece that reduces viscosity during injection, thanks to a sonic-activated dispensation.

The aim of this study is to investigate the cusps deformation of MOD cavities restored with different viscosity composite materials and different restorative techniques. The null hypothesis is that these materials and these layering techniques would condition the cusp deformation.

\section{Methods}

Two bulk-fill composites, largely differing in rheological properties and material composition, were used. Material characterization was achieved for both composites according to linear shrinkage and compressive test. Linear shrinkage was investigated in the direction perpendicular to the light curing source and five specimens $(5.0 \mathrm{~mm} \times 5.0 \mathrm{~mm} \times 1.5 \mathrm{~mm})$ for each material were positioned between the mechanical arms of an Instron extensometer (Instron Ltd., High Wycombe, UK). Linear shrinkage data were acquired up to $3600 \mathrm{~s}$ at a speed of $50 \mathrm{p} / \mathrm{s}$ using the National Instrument DAC (National Instruments, Austin, TX, USA).

Compression test was carried out on five cylindrical specimens ( $3 \mathrm{~mm}$ diameter and a $4 \mathrm{~mm}$ height) for each material thanks to an Instron 5566 (Instron Ltd.) testing machine, equipped with a 5 $\mathrm{kN}$ load cell and performed within one hour $(\mathrm{t} 0)$ or $72 \mathrm{~h}(\mathrm{t} 72 \mathrm{~h})$ from polymerization. Linear shrinkage and compression test data were analysed using two-way ANOVA followed by Tukey's test at a critical value of 0.05 .

Forty extracted upper premolars were selected and mesio-occlusal-distal cavities, with a $4 \mathrm{~mm}$ cavity depth and $3 \mathrm{~mm}$ intercuspidal width, were prepared. MOD cavities dimensions were measured and recorded. Teeth were divided in two groups for the two different bulk-fill materials and then divided in subgroups according to the restorative technique. With the bulk-fill technique, cavities were restored through a $4 \mathrm{~mm}$ increment, while with the incremental technique two increments of $2 \mathrm{~mm}$ each. After MOD cavities preparation, the adhesive protocol was achieved to apply the adhesive system Optibond SE (Kerr Corporation). Teeth were then fixed in an aluminium cylinder filled with PMMA acrylic resin and positioned on the thermoblock system (Falc, Genova, Italy) to heat the samples at $35{ }^{\circ} \mathrm{C}$. The variation of the distance between cusps during photopolymerization was measured using the Instron Extensometer A1439-1014 (Instron Ltd.). Light power level, of the curing unit Swiss Master Light (EMS) at an intensity level of $1000 \mathrm{~mW} / \mathrm{cm}^{2}$ and exposure time of $20 \mathrm{~s}$, was monitored by a filtered photocell. Data of cusps deformation was acquired at a speed of $50 \mathrm{p} / \mathrm{s}$ up to $3600 \mathrm{~s}$ using the National Instrument DAC (National Instruments). For each restorative technique and each bulk-fill material, five specimens were used, and data were analyzed using two-way ANOVA followed by Tukey's test at a critical value of 0.05 . 


\section{Result and Discussions}

For both composites a steep shrinkage profile is visible as the light is switched on and shrinkage increases during the dark reaction phase, and values recorded at $3600 \mathrm{~s}$ are significantly higher than those at $300 \mathrm{~s}$. Mean shrinkage values of low-viscosity composite, at $300 \mathrm{~s}$ and $3600 \mathrm{~s}$, are significantly higher than those of high-viscosity composite. The higher shrinkage of low-viscosity composite is directly related to the amount of the polymericmatrix.

Compressive strength values and Young modulus, at both time points, of the high-viscosity composite are significantly higher than those of the low-viscosity composite, suggesting that this material is stiffer. Instead, strain to failure of the low-viscosity composite is significantly higher than that of high-viscosity, suggesting that this material is more compliant.

The compressive strength and Young's modulus in compression measured for the high-viscosity composite are directly ascribed to the amount of the filler reinforcement phase.

For the high-viscosity composite, the incremental layering technique achieves higher mean values of cusps distance variation than the bulk-fill technique, although these values are not significantly higher. Instead, for the low-viscosity composite, the incremental layering technique achieves significantly higher values of cusps distance variation than the bulk-fill technique.

The low-viscosity material has a significantly lower Young's modulus than the high-viscosity material and it promotes elastic deformation, while it is more compliant and it reduces the amount of stress on the cavity walls. The high-viscosity material is stiffer and generates high stress at the cavity walls, and this stress is compensated by the lower shrinkage of the material.

\section{Conclusions}

Both mechanical properties and volumetric shrinkage are important parameters that can affect cusps distance variation, while materials with different viscosity and different restorative techniques do not influence significantly the cuspidal deformation.

Conflicts of Interest: The authors declare no conflict of interest.

\section{References}

1. Braga, R.R.; Ballester, R.Y.; Ferracane, J.L. Factors involved in the development of polymerization shrinkage stress in resin-composites: A systematic review. Dent. Mater. 2005, 21, 962-970.

2. De Santis, R.; Gloria, A.; Prisco, D.; Prisco, D.; Amendola, E.; Puppulin, L.; Pezzotti, G.; Rengo, S.; Ambrosio, L.; Nicolais, L. Fast curing of restorative materials through the soft light energy release. Dent. Mater. 2010, $26,891-900$.

3. Kwon, Y.; Ferracane, J.; Lee, I.B. Effect of layering methods, composite type, and flowable liner on the polymerization shrinkage stress of light cured composites. Dent. Mater. 2012, 28, 801-809.

4. Kim, R.J.; Son, S.A.; Hwang, J.Y.; Lee, I.B.; Seo, D.G. Comparison of photopolymerization temperature increases in internal and external positions of composite and tooth cavities in real time: Incremental fillings of microhybrid composite vs. bulk filling of bulk fill composite. J. Dent. 2015, 43, 1093-1098.

5. Ilie, N.; Bucuta, S.; Draenert, M. Bulk-fill resin-based composites: An in vitro assessment of their mechanical performance. Oper. Dent. 2013, 38, 618-625.

6. Chesterman, J.; Jowett, A.; Gallacher, A.; Nixon, P. Bulk-fill resin-based composite restorative materials: A review. Br. Dent. J. 2017, 222, 337.

7. Lima, R.B.; Troconis, C.C.; Moreno, M.B.; Murillo-Gomez, F.; De Goes, M.F. Depth of cure of bulk fill resin composites: A systematic review. J. Esthet. Restor. Dent. 2018, 30, 492-501.

8. El-Safty, S.; Akhtar, R.; Silikas, N.; Watts, D.C. Nanomechanical properties of dental resin-composites. Dent. Mater. 2012, 28, 1292-1300.

Publisher's Note: MDPI stays neutral with regard to jurisdictional claims in published maps and institutional affiliations. 
(C) 2020 by the authors. Submitted for possible open access publication under the terms and conditions of the Creative Commons Attribution (CC BY) license (http://creativecommons.org/licenses/by/4.0/). 